\title{
Resposta diferencial das cultivares de algodoeiro a Alternaria macrospora
}

\author{
Yeshwant Ramchandra Mehta1, , Eliria Teixeira², Helio Cunha², José Erivaldo³, Onaur Ruano ${ }^{1}$
}

${ }^{1}$ IAPAR, Caixa Postal 481, Londrina, PR; ${ }^{2}$ Agência Rural, Goiânia, GO; ${ }^{3}$ CNPsoja, Embrapa, CP 231, Londrina, PR. <yrmehta@ pr.gov.br> Data de chegada: 28/09/2004. Aceito para publicação em: 30/06/2005.

\begin{abstract}
Mehta, Y.R; Teixeira, E. A; Cunha, H.F. ; Erivaldo, J; Ruano, O. Differential response of cotton cultivars to Alternaria macrospora. Summa Phytopathologica, v.32, n.2, p.186-187, 2006.

The differential response of 32 commercial cotton cultivars to $A$. macrospora was studied under greenhouse conditions. Twenty to twentyfive days old plants were inoculated in 25 repetitions in a randomized block design. The cultivars were grouped using the Scott \& Knott analysis. Complete resistance was not found and all cultivars were susceptible to the pathogen. Differential reaction within

the plants of the same cultivar was observed. However, when some resistant plants of cultivars BRS Antares and Fibermax 986 were inoculated using a mixture of nine randomly selected isolates of $A$. macrospora, the plants maintained their resistance. Further research is necessary to find sources of resistance to this pathogen in other species of Gossypium.
\end{abstract}

Additional keywords: Gossypium hirsutum, varietal resistence, Alternaria.

\section{RESUMO}

Mehta, Y.R; Teixeira, E. A; Cunha, H.F.; Erivaldo, J; Ruano, O. Resposta diferêncial das cultivares de algodoeiro a Alternaria macrospora. Summa Phytopathologica, v.32, n.2, p.186-187, 2006.

Estudou-se a resposta diferencial de 32 cultivares comerciais do algodoeiro a $A$. macrospora em casa de vegetação. A inoculação foi realizada em plântulas de 20-25 dias de idade com 25 repetições, utilizando-se o delineamento experimental de blocos ao acaso. As cultivares foram agrupadas através de análise de Scott \& Knott. Resistência completa não foi encontrada, sendo que todas as cultivares foram suscetíveis. Houve diferença entre reação de plantas da mesma cultivar. Não obstante, quando algumas plantas das cvs. BRS Antares e Fibermax 986, que mostraram resistência, foram inoculadas com mistura de nove isolados escolhidos ao acaso, as mesmas mantiveram sua resistência a esta mistura. Trabalhos futuros deverão ser realizados para encontrar fontes de resistência a este patógeno em outras espécies de Gossypium.

Palavras-chave adicionais: Gossypium hirsutum, resistência varietal, Alternaria.

O algodoeiro é uma cultura de alta importância para o Brasil. Nos últimos anos, grande parte dos custos de produção foram atribuídos ao combate de novas pragas e entre 1996 e 2002, ao combate da Alternaria causada por Alternaria spp (1), e à nova doença "mancha preta", causada por Stemphylium solani (5). Há alguns anos atrás, a Alternaria era considerada a doença do final de ciclo da cultura, mas em anos recentes, ela é considerada a doença de maior importância econômica em todas as regiões produtoras de algodão, podendo ocasionar perdas apreciáveis em rendimento dependendo da cultivar e das condições climáticas $(1,2,3,4,6,7,8,9,11)$. Em anos recentes, seis novas cultivares estão sendo introduzidas para o cultivo comercial nos diversos estados brasileiros (cvs. BRS Araueira, Fabrika, Fibermax, Makina, Stoneville 474 e Sure Grow). Não há informação suficiente sobre o comportamento de cultivares em relação as populações de Alternaria spp. ocorrendo nas principais regiões produtoras de algodão. O objetivo do presente trabalho foi estudar o comportamento de cultivares comerciais utilizadas nas principais regiões produtoras de algodão do Brasil.

Sementes genéticas de 32 cultivares, foram adquiridas através da Fundação Mato Grosso, Rondonópolis, MT, e outras entidades oficiaís dos estados de Goiás, São Paulo e Paraná, e foram cultivadas em casa de vegetação em vasos plástico contendo solo esterilizado a $21^{\circ} \mathrm{C}$ e com fotoperíodo de $12 \mathrm{~h}$ luz/escuro. A inoculação foi realizada em plântulas de 20-25 dias de idade com 25 repetições (25 plantas por cultivar) utilizando o delineamento experimental de blocos ao acaso. As cultivares foram agrupadas através de análise de Scott \& Knott (10).

Colônias de um isolado monospórico mais agressivo no. 510 de A macrospora da coleção do IAPAR (6), cultivadas por 8-10 dias em meio de cultura V8-agar foram utilizadas para preparo do inóculo. A suspensão de conídios foi ajustada a 5,0 X $10^{4}$ 
conídios/ml. Um pincel embebido na suspensão de inoculo foi passado individualmente em cada folha da plântula sem causar ferimento (5), nas duas folhas mais novas e completamente expandidas por planta. Logo após a inoculação, as plantas foram transferidas para uma câmara com umidificador onde permaneceram 48 horas no escuro a temperatura de $21^{\circ} \mathrm{C}$ e umidade relativa do ar de aproximadamente $100 \%$. Após este período foram transferidas para a casa de vegetação.

Para o teste de resistência em plântulas, as observações sobre a severidade da doença foram realizadas 8 dias após a inocu-

Tabela 1. Resposta diferencial de 33 cultivares do algodoeiro à $\mathrm{Al}$ ternaria macrospora oito dias após a incubação em casa de vegetação.

\begin{tabular}{|c|c|c|}
\hline Cultivar & $\begin{array}{c}\% \text { área foliar } \\
\text { infectada* }\end{array}$ & Agrupamento** \\
\hline BRS ANTARES & 28,0 & 1 \\
\hline CPPDETEC 4-4 & 28,8 & 1 \\
\hline FIBERMAX 986 & 29,2 & 1 \\
\hline ITA 97 & 29,8 & 1 \\
\hline STONEVILLE 474 & 30,0 & 1 \\
\hline PR 94227918 & 30,4 & 1 \\
\hline IAC 23 & 30,8 & 1 \\
\hline IAC 24 & 33,8 & 2 \\
\hline ITA 90 & 34,0 & 2 \\
\hline EPAMIG PRECOCE 1 & 34,2 & 2 \\
\hline SM3 & 35,0 & 2 \\
\hline FMT 95743 & 36,4 & 2 \\
\hline DELTAOPAL & 37,6 & 2 \\
\hline FIBERMAX 966 & 38,6 & 2 \\
\hline IAC 22 & 39,2 & 2 \\
\hline BRS AROEIRA & 39,4 & 2 \\
\hline IPR 94 & 40,6 & 2 \\
\hline COODETEC 402 & 42,6 & 3 \\
\hline FABRIKA & 44,2 & 3 \\
\hline PR 97-1522 & 45,0 & 3 \\
\hline ITA 96 & 45,6 & 3 \\
\hline BRS FACUAL & 45,6 & 3 \\
\hline EPAMIG LIÇA & 46,8 & 3 \\
\hline IAPAR 71 & 47,2 & 3 \\
\hline CNPA PRECOCE 2 & 47,2 & 3 \\
\hline IPR 96 & 48,2 & 3 \\
\hline SATURNO & 49,8 & 3 \\
\hline MAKINA & 50,2 & 3 \\
\hline CNPA PRECOCE 1 & 50,2 & 3 \\
\hline FMT 97-1067 & 55,2 & 4 \\
\hline IPR 95 & 56,0 & 4 \\
\hline COODETEC 401 & 56,4 & 4 \\
\hline BRS IPE & 58,2 & 4 \\
\hline
\end{tabular}

* Inoculação realizada através de um pincel (5), utilizando-se uma concentração de $5 \times 10^{4}$ conidios $/ \mathrm{ml}$, do isolado mais agressivo no. 510 da coleção do IAPAR. A severidade da doença foi avaliada através de uma escala visual de porcentagem da área foliar infectada (5). ** Média de 25 plantas por cultivar. Agrupamento baseado na análise de Scott \& Knott (1974). Nível de significância do qui quadrado $=0,05000$. Cultivares com mesmo número não diferem entre si. lação utilizando-se uma escala visual de porcentagem de área foliar infectada (AFI) entre 0 e $100 \%$. O agrupamento das cultivares foi feito segundo análise Scott \& Knott (10).

Resistência completa não foi encontrada, sendo que todas as cultivares foram suscetíveis ou altamente suscetíveis ao isolado agressivo No. 510 de A. macrospora, nas inoculações artificiaís em casa de vegetação (Tabela 1). Houve muito variação entre as plantas da mesma cultivar. Não obstante, quando algumas plantas das cvs. BRS Antares e Fibermax 986 que mostraram resistência a isolado No. 510, foram inoculadas com uma mistura de nove isolados mais agressivos da coleção do IAPAR - Nos.13305, 13411, 13413, 13571, 13574, 13595, 13795, 13821, 13827, escolhidos ao acaso (6), em quantidades iguaís de conídios, as mesmas demonstraram sua resistência a esta mistura. Trabalhos futuros devem ser realizados para encontrar fontes de resistência a este patógeno em outras espécies de Gossypium.

\section{REFERÊNCIAS BIBLIOGRÁFICAS}

1. Cotty, P.J. Evaluation of cotton cultivar susceptibility to Alternaria leaf spot. Plant Disease, St. Paul, ,v.7, n.12, p.1082-1084. 1987.

2. Cia, E.; Fuzatto, M.G. Manejo de doenças na cultura de algodão. In: Cia, E.; Freire, E.C.; Santos, W.G. (Ed.). Cultura do algodoeiro. Piracicaba: Associação Brasileira para Pesquisa em Potassa e do Fosfato, 1999. p. 121-131.

3. Ephrath, J.E.; Shteinberg. D.; Drieshpoun, J.; Dinnor, A.; Mara$\mathrm{ni}$, A. Alternaria alternata in cotton (Gossypium hirsutum) cv. Acala: effects on gas exchange, yield components and yield accumulation. Netherlands Journal of Plant Pathology, Amsterdam, v. 95, n. 95, p.157-166, 1989.

4. Freire, C.E.; Farias, F.J.C.; Aguiar, P.H.; Araújo, A.E. Comportamento de novas cultivares e linhagens com relação a doenças no Centro-oeste - Safra 1998/99. In: Congresso Brasileiro de Algodão, 2., 1999. Anais. Campina Grande: Embrapa Algodão, 1999. p. 454-455.

5. Mehta, Y.R. Severe outbreak of Stemphylium leaf blight-a new disease of cotton in Brazil. Plant Disease, St. Paul, v.82, n. 3, p.333-336, 1998.

6. Mehta, Y.R.; Cassetari Neto, D.; Cia, E.; Pizzinatto, M.A.;Teixeira, E.A.; Cunha, H. variabilidade genética entre isolados de Alternaria macrospora do algodoeiro. Summa Phytopathologica, Jaboticabal, v.30, n. 4, p. 481-487. 2004.

7. Lima, E.F.; Carvalho; J.L.F.C.; Batista, F.A.S.; Santos, J.W. Avaliação do nível de resitência de linhagens e cultivares de algodoeiro à mancha de Alternaria. In: Reunião Nacional de Algodão, 8., 1995, IAPAR, Londrina, 1995. Anais. Londrina: Editora/Instituto Responsável, 1995. p. 110.

8. Ling, L.; Yang, J.Y. Stem blight of cotton caused by Alternaria macrospora. Phytopathology, St. Paul, v.31, n.1, p. 664-671, 1940.

9. Ruano, O. Controle de doenças de plantas. In: Zambolim, L.; Vale F.X.R. do (Ed.). Controle de doenças de plantas: grandes culturas. Viçosa: Universidade Federal de Viçosa, 1997. p. 556-609.

10. Scott, A.J.; Knott, M.A. Cluster analysis method for grouping means in the analysis of variance. Biometrics, Washington, v.30, n. 3, p. 507-512. 1974.

11. Watkin, G.M. Compendium of cotton diseases. St. Paul: American Phytopathological Society, 1981. 87p. 